\title{
Changes in Empathy of Nursing College Students: A Cohort Longitudinal Study
}

\author{
Jeong, Hyesun ${ }^{1) \odot} \cdot$ Lee, Keelyong ${ }^{2) \odot ~}$
}

Purpose: This study aimed to identify changes in sub-areas of empathy over the 4 years from admission to graduation of nursing college students. Methods: This descriptive survey study was conducted using a longitudinal cohort design. The participants in this study were 158 South Korean nursing students attending a university in Chungcheongbuk Province or Gyeonggi Province, all of whom passed the certification evaluation for the 4-year nursing educational institute. Data from 126 participants were analyzed. The level of empathy was measured five times from March 2012 to December 2015. Empathy was identified using a multi-dimensional measurement tool consisting of four sub-constructs of cognitive and emotional aspects: (1) perspective taking, (2) fantasy, (3) empathic concern, and (4) personal distress. Data were analyzed using SPSS version 25 to provide descriptive statistics of the participants' general characteristics and empathy level and to perform repeated-measures analysis of variance for the sub-constructs empathy. Results: Perspective taking $(F=13.08, p<.001)$ and personal distress $(F=5.24, p=.001)$, but not fantasy or empathic concern, showed significant differences over time. Conclusion: Cognitive empathy (perspective taking) and emotional empathy (personal distress) improved. Intervention programs should be developed to maintain and strengthen changes in empathy in nursing education.

Key Words: Empathy; Longitudinal studies; Nursing education; Nursing students

Received Apr 17, 2021 Revised Jul 7, 2021 Accepted Nov 15, 2021

Corresponding author: Lee, Keelyong https://orcid.org/0000-0001-5185-6827

Department of Nursing, Suwon Science College

288 Seja-ro, Jeongnam-myeon, Hwaseong 18516, Korea

Tel: 031-350-2347, Fax: +82-31-350-2076, E-mail: lkl@ssc.ac.kr 


\section{INTRODUCTION}

Empathy refers to a psychological and emotional state in which one person is aware of another's internal quorum and its emotional elements without forgetting that he or she is a person [1]. In the field of nursing studies, empathy has been consistently reported to be an essential factor in the establishment of therapeutic relationships with patients and an important condition for the improvement of nursing quality $[2,3]$. However, a high level of empathy is difficult to acquire in a short time period. Therefore, it has been suggested that empathy training should be conducted continuously and systematically throughout the entire undergraduate nursing course [3]. Accordingly, undergraduate nursing courses should not only teach the theory of empathy but also provide hands-on training via in-school, clinical, and simulation practices, as well as a separate program to promote empathy [4-7].

Most of the prior studies that looked at changes in the empathy ability of nursing college students apply the cross -sectional research design by identifying differences between grades at one point or comparing data from a year later. Therefore, there was a limit to how empathy changed with the promotion of the grade throughout the entire nursing curriculum of the same subject. Moreover, the results of these studies have been very inconsistent. Some studies reported no difference in empathy throughout different years of study [8-10], while others reported an increased level of empathy [11]. Another study [12] reported that the level of empathy decreased as their grade level increased. This is contrary to expectations that empathy will improve if students are simultaneously gaining experience in clinical practice and being educated on empathy. As it is difficult to find consistent results in research on the level of empathy among nursing students, it is meaningful to try cohort-longitudinal research to track changes in empathy from the time of admission to the time of graduation.

The choice of measuring tools is important to understand the ability of empathy. The interpersonal reactivity index (IRI) of Davis [13] is a multidimensional empathy measurement tool that includes cognitive and emotional empathy. Davis [13] describes empathy as a multidimensional concept that involves perspective taking, fantasy, empathic concern, and personal distress. "Perspective taking" and "fantasy" are categorized as elements of cognitive empathy, where "perspective taking" refers to the tendency to voluntarily take another person's psychological perspective or attitude, and "fantasy" refers to the tendency to transpose oneself with the feelings or actions of fictional characters in books, movies, and plays [13]. "Empathic con- cern" and "personal distress" are categorized as elements of emotional empathy, where "empathic concern" indicates a tendency to feel type-oriented sympathy and to care about others who are unhappy, and "personal distress" refers to a tendency to feel uncomfortable and experience pain due to other people's misfortune or suffering [13].

Empathy-related prior studies have shown that perspective taking as the cognitive empathy is positively correlated with personal growth, purpose in life, and environmental mastery and also has an effect on psychological well-being [14-16]. In addition, personal distress as emotional empathy also is negatively correlated with autonomy, environmental mastery, and self-acceptance, while positively correlated with Post Traumatic Stress Disorder (PTSD) and General Psychological Distress (GPD) [15]. Moreover, participants who score high in perspective taking tended to use active response strategies in stressful situations, while participants who score high in perspective taking and low in personal distress were found to have a low level of stress perception [17]. Based on the results of these studies, it is reasonable to interpret empathy as a multi-dimensional concept rather than a single dimension and find meaning.

The nursing practice generally aims for a high level of empathy. However, it is reported that people experience both empathy fatigue and exhaustion when their level of empathy is high [18]. Thus, it can be thought that there was an interaction between cognitive empathy for the client and emotional response according to the emotional empathy level of the nursing provider. Therefore, rather than simply considering the nursing providers' empathy level in target nursing, it would be necessary to find meaning by considering the relationship between functions and the sub-area of empathy.

Prior studies that identified the empathy of nursing college students used the Jefferson Empathy Scale (JES), which measures cognitive empathy [19]. Further, considering each sub-area of empathy [13-17] during the nursing education process, it is meaningful to look at sub-area changes. In this study, the change of empathy by sub-area in nursing students from the time of admission to graduation was investigated. The results were used as basic data for effective empathy enhancement education and positive empathy competency.

\section{METHODS}

\section{Research Design}

This study was a cohort longitudinal research to identi- 
fy changes in each sub-area of empathy over the four years from admission to graduation.

\section{Participants}

This study evaluated 158 nursing students attending accredited nursing education programs at a university in Chungcheongbuk-do and a university in Gyeonggi-do, who volunteered to participate in the study. The number of participants was calculated by $\mathrm{G}^{*}$ power 3.1.9 program. As a result of entering the following inputs: power (1$\beta)=.90$, significance level $(\alpha)=.05$, effect size $=0.15$, group number $=1$, measured Time $=5$, and Correlations among measurements $=.50$ for the repeated measure of ANOVA, the minimum sample size was determined to be 70 . The effect size was determined to be an intermediate size based on the prior literature [20]. However, data were collected from 158 students, and a potential dropout rate of $50 \%$ due to military enlistment and leaves of absence was considered. Among the students who participated in the study, 2, 18, 9, and 2 were eliminated from the second, third, fourth, and fifth data collections, respectively. A total of 126 students were finally analyzed, except for 1 who had insufficient responses (Figure. 1).

\section{Instrument}

This study measured empathy using a Korean version of the Interpersonal Reactivity Index (IRI), developed by Davis [13] and translated by Kang et al. [21] to verify validity and reliability with factor analysis. This instrument consists of four area of perspective taking, fantasy, empathic concern, and personal distress, each sub-area had seven items, consisting of a total of 28 items. The score range of the Korean version of the instrument has is from 1 to 5. The higher the score, the higher the level of empathy. Davis [13] did not produce a total score, as he suggested that there was an area that represented a negative correlation so that scores for each sub-area would be used. Cronbach's $\alpha$ s of the Korean version of the instrument were as follows: perspective taking (.61), fantasy (.81), empathic concerns (.73), and personal distress (.71). In addi-

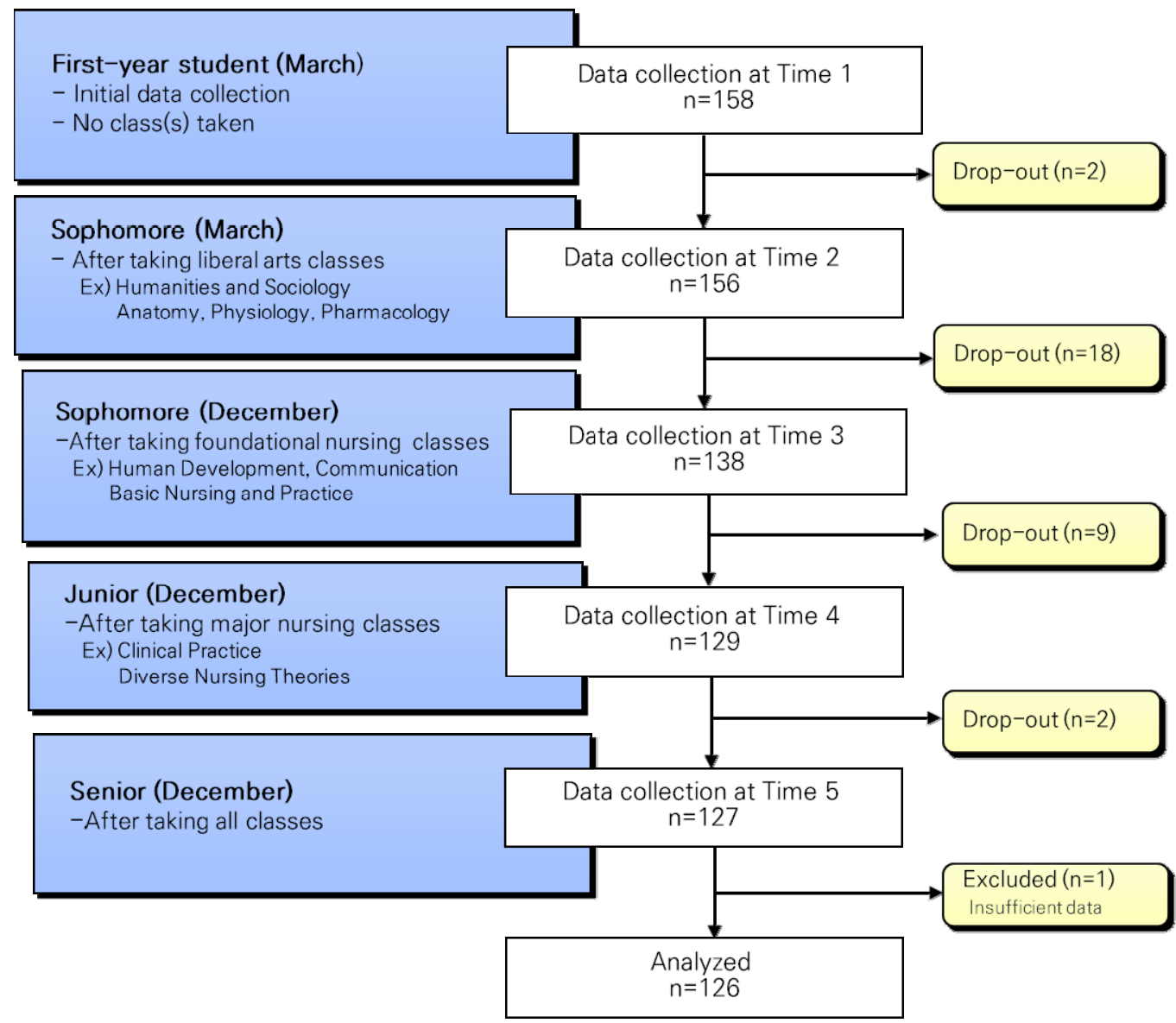

Figure 1. Procedure for data collection and sample size. 
tion, the Cronbach's $\alpha$ values in this study were .71 (perspective taking), .79 (fantasy), .70 (empathic concern), and .82 (personal distress).

\section{Data Collection}

The empathy was measured five times between March 2012 to December 2015 (Figure 1). However, the researchers did not directly collect the data. Instead, a research assistant distributed the questionnaire and collected data from the representative of the nursing department in 2012. The same research assistant collected data for the rest of the study period.

In March 2012, the research assistant verbally explained the guidance to the first-year nursing students in the classroom-the nursing students voluntarily signed their consent to participate in the study at the data collection point. The second and third measurements of empathy were collected in March and December of the sophomore year, respectively. The fourth and fifth measurements of empathy were collected in December of the third and fourth years. A total of 126 people were included in the final analysis. Two were omitted in the second data collection, 18 in the third, nine in the fourth, two in the fifth, and one who had a generally insufficient response. There was higher attrition in the third round of data collection because many male students applied for a leave of absence from school to fulfill the mandatory military services requirement during this period.

The timing of the data collection was determined based on the curriculum. In other words, it was set up in consideration of the completion of theoretical and practical courses that could affect the level of empathy. This study's first measurement was in March 2012 at the time of the participants' admission to the nursing department, to establish an initial level of empathy before any effect of the nursing curriculum.

The second measurement was conducted in March 2013 of the second year, after the first year of the liberal arts and natural sciences curriculum. Thus, we could evaluate the effect on the participants' level of empathy during courses such as anatomy, physiology, and pharmacology along with various humanities and social sciences, before starting their nursing major coursework.

In December 2013 of the second year, we conducted the third measurement. This was when the basic humanities and social studies subjects of human development and communication theory had been completed. Further, it was the period through which basic nursing, nursing practices, knowledge, and empathy for the development stages of human life could be improved. Furthermore, in these courses, critical thinking, and the nursing process were learned and applied to the specific methods and applications of therapeutic communication, which hypothetically could expand empathy.

The fourth measurement period was in December 2014 of the third year, after completing nursing major theoretical subjects and clinical practice subjects, including psychiatric nursing. In particular, training was conducted to form relationships with humans by actually applying knowledge learned through theoretical courses to clinical practice while completing practicums. Additionally, cognitive empathy could be significantly improved by identifying the needs of patients and planning, implementing, and evaluating nursing care to address them.

The fifth measurement was implemented in December 2015, the final year, when all theoretical and practical subjects included in the curriculum had been completed. This period is a time when the overall effect of the curriculum on empathy could be identified.

Compared to the curriculum of the two schools that conducted data collection, the curriculum of the liberal arts course was somewhat different. Nonetheless, there were no differences in credit allocation and timing in communication, in-school and clinical practice subjects.

\section{Data Analysis}

The collected data were analyzed using IBMSPSS/WIN (version 25.0; IBM Corp., Armonk, NY, USA). The general characteristics and level of empathy of the participants were presented using the descriptive statistics, and the changes in the sub-area of empathy were identified through repeated measures of ANOVA, and the reliability of the instrument was presented as Cronbach's $\alpha$.

\section{Ethical Consideration}

This study was conducted after obtaining approval from the Institutional Review Board (IRB) to the research belongs (KNU_IRB_2015-15). To the participants, the research assistant explained the purpose of the research, the contents of the questionnaire, the number of times to complete it, the voluntary nature of participation in the research, withdrawal from the research, anonymity, and protection of private information. If a nursing student voluntarily signed an agreement to participate in the research after hearing the explanation from the research assistant, he or she was included as a participant. 


\section{RESULTS}

\section{Characteristics of the Participants}

The mean age of the participants was $19.27 \pm 3.27$ years (range 19 39 years), and all 126 were female. $52.4 \%$ of the participants had no religion and $56.3 \%$ of the participants said they had the aptitude and a sense of calling for nursing, followed by $31.0 \%$ who chose nursing for ease of employment and $12.7 \%$ who pursued nursing based on recommendations from others (Table 1).

Table 1. Characteristics of Subjects

$(N=126)$

\begin{tabular}{llc} 
Variables & Categories & $\begin{array}{c}\mathrm{n}(\%) \text { or } \\
\mathrm{M} \pm \mathrm{SD}\end{array}$ \\
\hline Age (year) & $19 \sim 39$ & $19.3 \pm 3.3$ \\
Gender & Female & $126(100.0)$ \\
Religion & No & $66(52.4)$ \\
& Yes & $60(47.6)$ \\
Motive for & Aptitude for nursing/calling & $71(56.3)$ \\
admission & Ease of getting a job & $39(31.0)$ \\
& Recommendation from others & $16(12.7)$ \\
\hline
\end{tabular}

\section{Changes in Nursing Students' Empathy}

As a result of analyzing the collected data, first of all, in the case of "perspective taking", the test of the sphericity assumption prior to performing the repeated measurement variance analysis showed that this assumption was not met $(p=.003)$ and the ANOVA was performed using Huynh-Feldt's revised test statistic. The analysis showed that the score for perspective taking' was 3.50 (Time 1), 3.56 (Time 2), 3.52 (Time 3), 3.72 (Time 4), and 3.79 (Time 5). In the case of "perspective taking", the level of improvement was weak in Time 2 and Time 3 compared to Time 1, but the score increased significantly from Time 4 when the third years curriculum was completed to Time 5 when all the curriculum was completed. Additionally, these changes over time were statistically significant $(\mathrm{F}=$ $13.08, p<.001)$. The post-test analysis of the difference suggests that the score of "perspective taking" varies significantly between Time 1 and Time 4 between Time 1 and Time 5 .

Furthermore "fantasy" also indicates that the test of the sphericity assumption did not meet the assumption $(p=.005)$. An analysis of variance was performed using HuynhFeldt's revised test statistics. In the case of 'fantasy', the scores were 3.81 (Time 1), 3.86 (Time 2), 3.79 (Time 3), 3.77
(Time 4), 3.8 (Time 5). In other words, the "fantasy" was somewhat higher at Time 2 compared to Time 1 , but Time 3 , Time 4, and Time 5 were suggested to be lower than Time 1. However, this pattern of "fantasy" changes as the school year increased was not statistically significant $(\mathrm{F}=$ $0.87, p=.483$ ).

The empathic concern was analyzed through the tests of within-subject effects, as the test of the sphericity test met the assumption $(p=.089)$. The analysis showed that scores for "empathic concern" were 3.78 (Time 1), 3.78 (Time 2), 3.70 (Time 3), 3.77 (Time 4), and 3.83 (Time 5). In other words, this pattern of "empathic concern" was not statistically significant, although it decreased slightly in time 3 and 4 compared to the reference point (time 1), and rose again in time 5 as the school year progressed.

Finally, the "personal distress" scores were tested for sphericity assumptions, and the analysis of variance was performed using the revised test statistic of Huynh-Feldt, which indicated that the assumptions were not met $(p<$ .001). The analysis showed that the score for "personal distress" was 3.10 (Time 1), 3.18 (Time 2), 3.18 (Time 3), 3.04 (Time 4), and 2.95 (Time 5). "Personal distress" increased scores at time 2 and time 3 compared to time 1, but decreased at times 4 and 5 , and these changes over time were statistically significant $(\mathrm{F}=5.24, p=.001)$. The post-test analysis suggests that the scores of the personal distress vary significantly between time 1 and 4 , time 2 and 4 , time 2 and time 3 and 4, and time 3 and 5 (Table 2).

\section{DISCUSSION}

This study was conducted on nursing students to identify changes in each sub-area of empathy over the four years from admission to graduation. The results show that the average score for each "perspective taking" time was $3.50,3.56,3.52,3.72$, and 3.79, respectively, which represented a significant change. There were also significant differences in times 1 and 4 , and times 1 and 5, which resulted in a significant increase by the end of the third and fourth years compared to their year of admission. Furthermore, the average score for "fantasy" was 3.81, 3,86, 3.79, 3.77 , and 3.80 , respectively, which represented no significant change.

The results from this study were similar to those of a previous study [11], which showed a higher level of empathy in older grades. However, this was contrary to previous studies $[12,22,23]$ that showed a low level of empathy in senior year medical and nursing students. This study and prior study differ in measurement tools and survey points, making it difficult to directly compare results. 
Table 2. Changes in Nursing Students' Empathy

\begin{tabular}{|c|c|c|c|}
\hline \multirow{3}{*}{ Variables } & \multirow{3}{*}{ Times $^{\dagger}$} & Descriptive statistics & Significant test \\
\hline & & \multirow{2}{*}{$\mathrm{M} \pm \mathrm{SD}$} & RM-ANOVA \\
\hline & & & $\mathrm{F}(p)$ \\
\hline \multirow[t]{6}{*}{ Perspective taking } & Time $1^{\mathrm{a}}$ & $3.50 \pm 0.60$ & $13.08(<.001)$ \\
\hline & Time $2^{\mathrm{b}}$ & $3.56 \pm 0.58$ & \\
\hline & Time $3^{c}$ & $3.52 \pm 0.56$ & \\
\hline & Time $4^{\mathrm{d}}$ & $3.72 \pm 0.55$ & \\
\hline & Time $5^{\mathrm{e}}$ & $3.79 \pm 0.51$ & \\
\hline & Post-hoc comparisons & $\mathrm{a}, \mathrm{b}, \mathrm{c}, \mathrm{a}<\mathrm{d}, \mathrm{e}$ & \\
\hline \multirow[t]{6}{*}{ Fantasy } & Time 1 & $3.81 \pm 0.64$ & $0.87(.483)$ \\
\hline & Time 2 & $3.86 \pm 0.60$ & \\
\hline & Time 3 & $3.79 \pm 0.69$ & \\
\hline & Time 4 & $3.77 \pm 0.65$ & \\
\hline & Time 5 & $3.80 \pm 0.65$ & \\
\hline & Post-hoc comparisons & - & \\
\hline \multirow[t]{6}{*}{ Empathic concern } & Time 1 & $3.78 \pm 0.55$ & $2.26(.062)$ \\
\hline & Time 2 & $3.78 \pm 0.54$ & \\
\hline & Time 3 & $3.70 \pm 0.60$ & \\
\hline & Time 4 & $3.77 \pm 0.61$ & \\
\hline & Time 5 & $3.83 \pm 0.52$ & \\
\hline & Post-hoc comparisons & - & \\
\hline \multirow[t]{6}{*}{ Personal distress } & Time $1^{\mathrm{a}}$ & $3.10 \pm 0.68$ & $5.24(.001)$ \\
\hline & Time $2^{\mathrm{b}}$ & $3.18 \pm 0.66$ & \\
\hline & Time $3^{c}$ & $3.18 \pm 0.64$ & \\
\hline & Time $4^{\mathrm{d}}$ & $3.04 \pm 0.63$ & \\
\hline & Time $5^{\mathrm{e}}$ & $2.95 \pm 0.59$ & \\
\hline & Post-hoc comparisons & $\mathrm{a}, \mathrm{b}<\mathrm{d}, \mathrm{e}, \mathrm{c}<\mathrm{d}, \mathrm{e}$ & \\
\hline
\end{tabular}

${ }^{\dagger}$ Time 1: March of the first year, Time 2: March of the second year, Time 3: December of the second year, Time 4: December of the third year, Time 5: December of the fourth year.

However, an accurate understanding of nursing sentiment is possible with high cognitive empathy, which leads us to conclude that a significant rise in "perspective taking" is an encouraging result. It is important for nurses to accurately understand the emotional state of their patients in order to effectively meet their nursing needs in the clinical field. An accurate understanding of the patient's needs or emotional status and proper intervention must be provided to meet the nursing needs of the subject at the nursing site, in which cognitive empathy is essential. "Perspective taking" refers to the tendency or ability to adopt other people's perspectives or views, as opposed to fantasizing about the tendency to identify with fictional characters in books and movies [13]. If the level of "perspective taking" is high, nursing providers will be able to understand the patients' feelings and why they feel that way, enabling them to provide nursing interventions that meet the patients' individual needs. In prior studies [24], empathy was positively correlated with critical and analytical think- ing, especially with the sub-area of perspective taking" $[14,16]$. Cognitive understanding of others, analytical and critical thinking, and interpersonal skills are essential in the process of accurately identifying the needs of each individual patient. In this context, it is a positive sign that "perspective taking" has risen over time in this study.

As we reflect on the findings of educational interventions promoting empathy, it is necessary to understand why older students have increased cognitive empathy during admission. It has been suggested that an increase in age leads to an increase in maturity and empathy levels [11]. However, there were no differences in the levels of empathy across grades in many prior studies $[9,25,26]$. We cannot establish with certainty that the difference between one and two years of undergraduate courses resulted in significant differences in the level of empathy. Considering the results of this study, one reason behind the significant increase in the level of "perspective taking" in third and fourth years compared to the first years might be 
attributed to the effectiveness of the curriculum.

Nursing education institutions develop and operate curricula to train competent nurses. It is believed that the completion of major theoretical and practical courses, as well as liberal arts, helped improve the understanding of human and human reactions, communication level, critical thinking ability, and cognitive empathy. One major difference in the curriculum of the first, third, and fourth years is the completion of clinical practice courses. Clinical practice is when nursing students can gain a deep awareness of nursing [27] and when they can directly apply the nursing process to subjects based on their theoretical knowledge. Reflective discussion in nursing education has been reported as a major educational activity that helps with actual care and increasing empathy [23]. The clinical practice provides a good opportunity to train cognitive empathy through reflection, listening, and forming therapeutic relationships.

For "personal distress" corresponding to emotional empathy, the average scores from time 1 to 5 were 3.10, 3.18, $3.18,3.04$, and 2.95 respectively, which reflected a significant change. By time points, the difference was significant at times 1 and 5 , times 2 and 4 , times 2 and 5 , times 3 and 4 , and times 3 and 5 and showed a continuous decrease.

"Personal distress" has a negative correlation with autonomy, environmental control, and self-acceptance. However, it has a positive correlation with post-traumatic stress syndrome and general psychological distress $[14,15]$ and a negative effect on stress perception, coping, and psychological well-being [14-17]. In this context, it is considered a positive result that the level of "personal distress" in nursing students decreased with an increase in grade. It should contribute positively to the students coping with heavy academic and clinical stress.

Considering the correlation between the real sub-area of empathy, one can think that personal distress correlates with cognitive empathy perspective taking [13] and that the lower the personal distress, the higher the level of perspective taking. Therefore multi-dimensional empathy is useful when examining the relationships and meanings between sub-area rather than trying to interpret sub-area independently. Based on the results of this study, it is believed that the rise in the level of "perspective taking" has increased the control nursing students have over their emotions and rational judgment, thereby helping them to also control their "personal distress".

Previous studies have shown that simulation education, role play, and reflection can effectively enhance the capacity for empathy [6] and that educational effort for empathy enhancement in nursing education is possible
$[4,6]$. Therefore, the development and operation of curricula to promote empathy that plays a central role in therapeutic relationships is necessary. Emotional empathy from the patient's perspective may risk distortion or exaggeration; therefore, it is necessary to pay more attention to improving cognitive empathy rather than emotional empathy in nurses, who need to understand and help improve patients' health problems accurately. Furthermore, an upward effect of "perspective taking" can be expected if the level of "personal distress" is improved, which will also lead to an effective improvement in the level of empathy. Personal distress can be effectively improved through interventions such as mind-body medical skills and mindfulnesss [28]. As such [28], an attempt to integrate them in the nursing education curriculum is also needed.

The results of this study indicate that it is crucial to understand the change in empathic ability by sub-area from the time of admission to graduation. Specifically, the increase in cognitive empathy level through the progression of the nursing curriculum is a very encouraging result.

\section{CONCLUSION}

This study was conducted with nursing students to identify changes in each sub-area of empathy over the four years from admission to graduation. The results of this study showed that "perspective taking" within cognitive empathy significantly increased and "personal distress" within emotional empathy significant decreased with the progress in nursing school years. The sub-area characteristics of empathy are believed to reflect area-specific characteristics in the relationship, communication, and effect on nursing care; thus, the importance of access from a multidimensional perspective is verified.

The limitations of this study are as follows: First, it does not fully control for the presence of external factors such as clinical experience related to empathy and internal factors such as self-awareness, awareness of others, emotional awareness, and self-elasticity. Second, it does not specifically confirm whether the change in the student's empathy by grade can be directly attributed to the curriculum. Third, the participants did not demonstrate difference in the overall curriculum and clinical practice hours; they also did not unify the practice papers, practice guidance professors, or specific practice operation plans.

In subsequent studies, it is necessary to control the factors influencing empathy and establish a comparative group to confirm whether changes in nursing students' empathy can be attributed to the curriculum. We would 
recommend future studies that not only addresses these limitations but also explores strategies nurses can employ to improve cognitive empathy and better manage emotional empathy.

\section{CONFLICTS OF INTEREST}

The authors declared no conflict of interest.

\section{AUTHORSHIP}

Study conception and design acquisition - JH; Data collection - JH and LK; Data analysis \& Interpretation - JH; Drafting \& Revision of the manuscript - LK.

\section{REFERENCES}

1. Rogers CR. A way of being. New York: Houghton Mifflin Harcourt C Publishing Company; 1995. p. 140-141.

2. Brunero S, Lamont S, Coates M. A review of empathy education in nursing. Nursing Inquiry. 2010;17(1):65-74. https://doi.org/10.1111/j.1440-1800.2009.00482.x

3. Kunyk D, Olson JK. Clarification of conceptualizations of empathy. Journal of Advanced Nursing. 2001;35:317-325. https://doi.org/10.1046/j.1365-2648.2001.01848.x

4. Cunico L, Sartori R, Marognolli O, Meneghini AM. Developing empathy in nursing students: a cohort longitudinal study. Journal of Clinical Nursing. 2012;21:2016-2025.

https://doi.org/10.1111/j.1365-2702.2012.04105.x

5. Lee KC, Yu CC, Hsieh PL, Li CC, Cha YFG. Situated teaching improves empathy learning of the students in BSN program: a quasi-experimental study. Nurse Education Today. 2018;64: 138-143. https://doi.org/10.1016/j.nedt.2018.02.013

6. Levett-Jones T, Cant R, Lapkin S. A systematic review of the effectiveness of empathy education for undergraduate nursing students. Nurse Education Today. 2019;75:80-94.

https://doi.org/10.1016/j.nedt.2019.01.006

7. Park YS, Jun MH, Lee JA. A comparative study of the nursing education system in Republic of Korea and United States -focused on distance education and web based learning. Journal of Learner-Centered Curriculum and Instruction. 2020;20 (6):1173-1197. https://doi.org/10.22251/jlcci.2020.20.6.1173

8. McKenna L, Boyle M, Brown T, Williams B, Molloy A, Lewis B, et al. Levels of empathy in undergraduate nursing students. International Journal of Nursing Practice. 2012;18(3):246-251. https://doi.org/10.1111/j.1440-172X.2012.02035.x

9. Lauder W, Reynolds W, Smith A, Sharkey S. A comparison of therapeutic commitment, role support, role competency and empathy in three cohorts of nursing students. Journal of Psychiatric and Mental Health Nursing. 2002;9:483-491. https://doi.org/10.1046/j.1365-2850.2002.00510.x

10. Lovan S, Wilson M. Comparing empathy levels in students at the beginning and end of a nursing program. International Journal for Human Caring. 2012;16(3):28-31. https://doi.org/10.20467/1091-5710.16.3.28

11. Ouzouni C, Nakakis K. An exploratory study of student nurses' empathy. Health Science Journal. 2012;6(3):534-552.

12. Ward J, Cody J, Schaal M, Hojat M. The empathy enigma: an empirical study of decline in empathy among undergraduate nursing students. Journal of Professional Nursing. 2012;28(1): 34-40. https://doi.org/10.1016/j.profnurs.2011.10.007

13. Davis MH. A multidimensional approach to individual difference in empathy. JSAS Catalog of Selected Documents in Psychology. 1980;10(85):1-18.

14. Choi D, Minote N, Sekiya T, Watanuki S. Relationships between trait empathy and psychological well-being in Japanese university students. Psychology. 2016;7(9):1240-1247. https://doi.org/10.4236/psych.2016.79126

15. Nagamine M, Shigemura J, Fujiwara T, Waki F, Tanichi M, Saito $\mathrm{T}$, et al. The relationship between dispositional empathy, psychological distress, and posttraumatic stress response among Japanese uniformed disaster workers: a cross-sectional study. BMC Psychiatry. 2018;18(1):328.

https://doi.org/10.1186/s12888-018-1915-4

16. Hass BW, Anderson IW, Filkowski MM. Interpersonal reactivity and the attribution of emotional reactions. Emotion. 2015; 15(3):390-398. https:// doi.org/10.1037/emo0000053

17. Jang HS. The effects of self-disclosure and empathy on stress perception and stress coping strategy of university students. Korean Journal of Communication Studies. 2013;21(3):5-28.

18. Mottaghi S, Poursheikhali H, Shameli L. Empathy, compassion fatigue, guilt and secondary traumatic stress in nurses. Nursing Ethics. 2020;27(2):494-504. https://doi.org/10.1177/0969733019851548

19. Yu J, Kirk M. Evaluation of empathy measurement tools in nursing: systematic review. Journal of Advanced Nursing. 2009;65(9):1790-1806.

https://doi.org/10.1111/j.1365-2648.2009.05071.x

20. Ferri P, Rovesti S, Padula MS, D'Amico R, Di Lorenzo R. Effect of expert-patient teaching on empathy in nursing students: a randomized controlled trial. Psychology Research and Behavior Management. 2019;12:457-467.

https://doi.org/10.2147/PRBM.S208427

21. Kang I, Kee SW, Kim SE, Jeong BS, Hwang JH, Song JE, et al. Reliability and validity of the Korean-version of interpersonal reactivity index. Journal of Korean Neuropsychiatric Association. 2009;48(5):352-358.

22. Wilson SE, Prescott J, Becket G. Empathy levels in first-and third year students in health and non-health disciplines. American Journal or Pharmaceutical Education. 2012;76(2):24. https://doi.org/10.5688/ajpe76224

23. Eklund JH, Holmstrom IK, Lindqvist AO, Sundler AJ, Hoch- 
walder J, Hammar LM. Empathy levels among nursing students: a comparative cross-sectional study. Nursing Open. 2019;6:983-989. https://doi.org/10.1002/nop2.280

24. Günaydın N, Barlas GU. Determination the critical thinking and empathy disposition of nursing students. Middle Black Sea Journal of Health Science. 2015;1(3):1-8. https://doi.org/10.19127/mbsjohs.27159

25. Jeong HS, Lee KL. Empathy and clinical practice stress in nursing student. Journal of the Korean Academia-Industrial cooperation Society. 2015;16(9):6044-6052. https://doi.org/10.5762/KAIS.2015.16.9.6044

26. Ferri P, Rovesti S, Bonetti L, Stifani S, Panzera N, Lorenzo RD. Evaluation of empathy among undergraduate nursing stu- dents: a three-year longitudianl study, Acta BioMed Health Professions. 2019;90(11 Suppl):98-107.

https://doi.org/10.23750/abm.v90i11-S.8874

27. Tseng HC, Wang HH, Weng WC. Nursing students' perception toward the nursing profession from clinical practicum in baccalaureate nursing program-a qualitative study. Kaohsiung Journal of Medical Science. 2012;29:161-168. https://doi.org/10.1016/j.kjms.2012.08.027

28. van Vliet $\mathrm{M}$, Jong $\mathrm{M}$. Long-term benefits a mind-body medicine skills course on perceived stress and empathy among medical and nursing students. Medical Teacher. 2017;39(7):710-719. https://doi.org/10.1080/0142159X.2017.1309374 